\title{
Hydrological consequences of changes forest cover on watersheds of the Amur river basin
}

\author{
Galina Sokolova $^{* 1}$ Andrei Verkhoturov ${ }^{1}$ and Hiroshi Hayasaka ${ }^{2}$ \\ ${ }^{1}$ Mining Institute FEB RAS, 51 Turgenev st., Khabarovsk, 680000, Russia; \\ ${ }^{2}$ Arctic Research Center, Hokkaido University, Sapporo, Japan
}

\begin{abstract}
Observing the geographic environment change of watersheds is very important for understanding problem of influence on streamflow, which ranks fourth out of 23 hydrological problems highlighted at Vienna Catchment Science Symposium in April 2018. Watersheds of the Middle and Lower Amur, where main part of streamflow is formed, are covered with forests of various structures. Annual forest fires in the Amur basin lead to sharp decrease in transpiration and summarize evaporation, an increase in volume and rate of surface streamflow (slope) into river beds and, as a consequence an increase in river runoff. An increase frequency of fires entails a change in forest species composition. Despite fact that species of the stand within watershed grow up in same conditions (environment, climate, weather, fires) - total value of the areas of coniferous forests has a decrease, in contrast to deciduous species. This is consistent with the conclusions of Russian hydrologists about shift in Russia of the boundaries of middle taiga on north, which is justified by them using climatic models. Reduction of coniferous forests, which have a deeper root system and larger area of contact with atmospheric precipitation, contributes to a faster runoff of rainwater, contributing an increase streamflow. Moreover, a positive trend is also noted in synchronous dynamics of peaks of rain floods on the Amur near Khabarovsk. This corresponds to assessment of spatio-temporal variations of global terrestrial water storage changes of the Amur according measurements of the Earth's gravitational fields by GRACE satellite, carried out by foreign researchers. It has been suggested that with a descending trend in areas of coniferous forests, conditions will persist, contributing to increase in streamflow during the period of monsoon and frontal cyclonic rains.

Keywords: basin of the Amur River, watershed, streamflow, forest species composition, remote sensing, fire weather index, climate
\end{abstract}

\section{Introduction}

Study of the current state of forests in condition of wildfires, climate variability and human economic activity remains for decades an important aspect of understanding role global environment in various systems, including rivers. Streamflow is most valuable renewable water resource, therefore it is important to know what changes occur in geographic environment of basin, affecting on value of runoff, hydrological regime and water quality.

\footnotetext{
*Corresponding author: galvadsok@mail.ru
} 
On the territory of Russian part of Amur river basin, state of forest on watersheds in current century is reflected in [1]. Moreover, the analysis and estimate of forests affecting streamflow was carried out in comparison with previous decades of XX century, including the developments of russian and foreign researchers, using remote sensing data.

Modern climate models predict an increase the number of forest fires in regions of Russia. This is facilitated by an increase in the average annual air temperature and duration of growing season [2], an increase in frequency and intensity of weather anomalies associated with global climate change [3], affecting on natural physical environment and vegetation cover [4]. In this aspect, a very useful role in terms of preventing active fires is played by the developments of researchers based on information the detection of active hotspots from MODIS time-series dataset of low resolution (Terra and Aqua satellites) [5]. A new approach to predictive assessment of fires [6] is based on a comprehensive analysis of data on detection of hotspots and baric topography maps at levels 925,850 , and $500 \mathrm{hPa}$, constructed from NCEP and NCAR reanalysis data [7]. A classification of active forest fires and accompanying weather conditions has been developed. This method was approved on territories of the Republic of Sakha-Yakutia and Lower Amur basin [6, 8].

Catastrophic hydrological phenomena on the Amur, which continue to this day (2019 is the second historical flood maximum for observation period since 1896), are a reason to search for causes of hydrological anomalies. Research and development of the fourth problem of hydrology [9] continues by the authors of this paper. Emphasis is made on the predictive assessment of hydrological consequences in such conditions of disturbance forest cover on watersheds by fires.

\section{Experimental research technique}

As an object of research, the territory of Priamurye region was selected, which covers Russian part of the Amur basin and administratively belongs to subjects of Russian Federation such as: Khabarovsk Territory, Amur Region and the Jewish Autonomous Region, Fig.1.

The state of study area was analyzed for potential predisposition to occurrence of wildfires due to weather conditions. We used the method of calculating fire hazard of M.A. Sofronov [10]. Climatic indicators were obtained from data 50 weather stations for period April to October 1980-2009. The maps of the isolines distribution of maximum air temperature, amount of rainy days, dew point, relative air humidity and fire hazard index $\left(F_{I}\right)$ were constructed. Maximum temperature was selected and averaged over all years and seasons. The air humidity was estimated by sum of rainy days per month $(3 \mathrm{~mm} /$ day and more), then averaging was also carried out over all years and seasons. $F_{I}$ values were calculated for each month (April - October) [11] using the formula:

$$
F_{I}=\frac{T_{i}\left(T_{i}-T_{p i}\right) \cdot 30}{n_{i}}
$$

where $T$ - average of maximum values for month, air temperature $\left(\mathrm{C}^{\circ}\right)$;

$\mathrm{Tp}$ - monthly minimum dew point temperature $\left(\mathrm{C}^{\circ}\right)$;

$\mathrm{n}-$ number of days in a given month with precipitation $\geq 3.00 \mathrm{~mm} /$ day;

$i=1,2, \ldots, 7$ is the ordinal number of given month / period. 


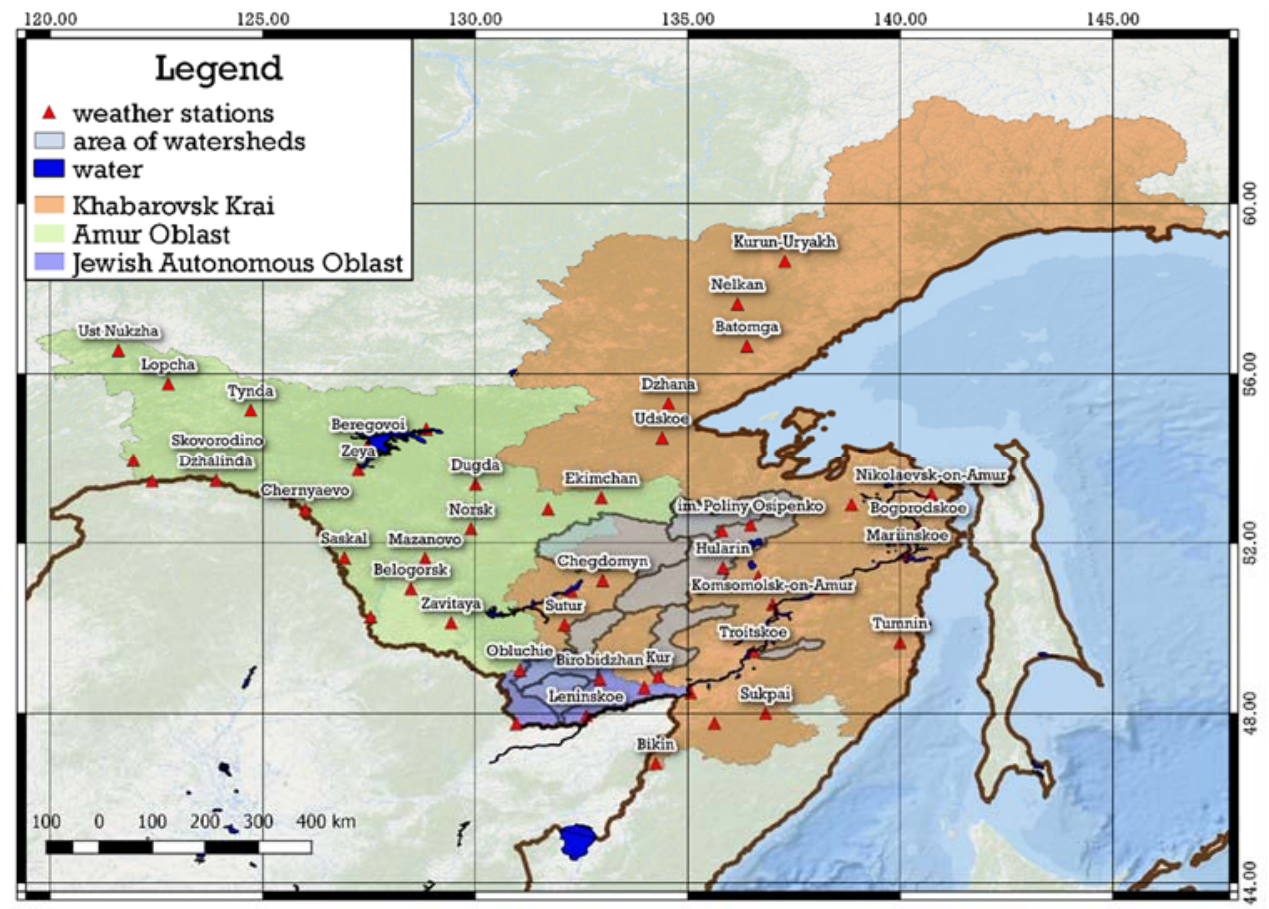

Fig. 1. Territory of the Priamurye region. Meteorological stations are marked with red triangles.

Data on the monthly minimum dew point temperature for a long-term period were calculated by formula:

where $a=17.27$;

$$
T_{p}=\frac{b \cdot\left(\frac{a \cdot T}{b+T}+\ln R H\right)}{a-\left(\frac{a \cdot T}{b+T}+\ln R H\right)}
$$

$b=237.7\left({ }^{\circ} \mathrm{C}\right)$;

$T$ - average of the maximum monthly air temperature $\left({ }^{\circ} \mathrm{C}\right)$;

$\mathrm{RH}-$ minimum monthly relative humidity (\%).

\section{Results and discussion}

The forests of the Amur basin are characterized by many fires in spring and autumn, in contrast to summer period. Over the past 20 years, the third peak of fires has also been observed - in the summer season, Fig. 2, however, spring fires remain the most numerous and active. So, on the territory of the basin of the Lower Amur and southern part of Khabarovsk Territory, spring fires account for about $50 \%$ of all fires per year [8]. 


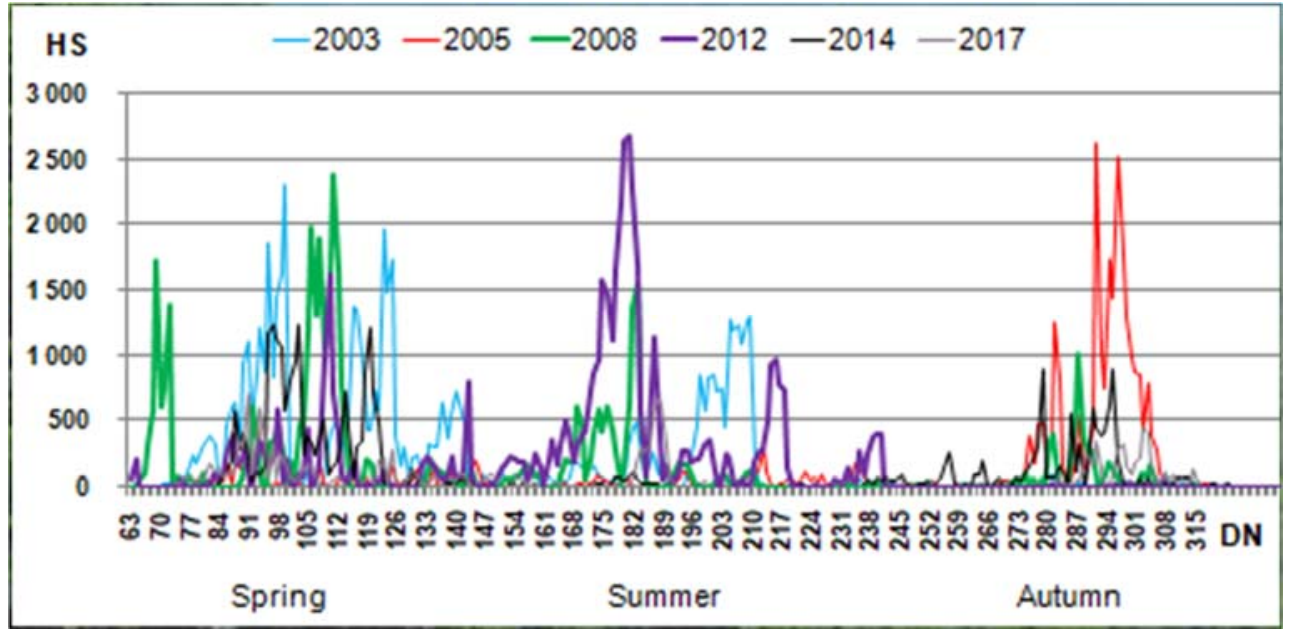

Fig. 2. Dynamics of daily data hotspots of territory Lower Amur basin and southern part of the Khabarovsk Territory (March 04 - November 14) for period 2003-2017. The horizontal axis is number day of year.

Note: Fire research [8], was partially supported by Center for International Forestry Research (CIFOR) with funding from the Japanese government.

Analysis of the distribution of average long-term $F_{I}$ values during fire season (April October) reflects the peculiarity of Far Eastern climate with dry springs, rainy summers, and warm autumn (Fig. 3a). The highest $F_{I}$ values in the period from April to June give grounds to assert that study area has a climatically determined potential predisposition to the occurrence of the most active wildfires in the spring. In autumn, fire hazard by $F_{I}$ value is two times lower than in spring Fig. $3 \mathrm{a}$.

In the long-term dynamics, the $F_{I}$ values in the spring period annually fluctuate within wide limits from 700 to 3000 units. Despite this, the general direction of $F_{I}$ fluctuations has a positive trend, Fig. 3b. A similar trend, but with a lesser rise, is observed in the fall. In the summer season, the trend would be negative, but due to extremely high value of the $F_{I}$ index (3500 units) in 1998 with catastrophic fires, the trend reached zero direction.

In fig. 4 shows isolines distribution of fire hazard index in spring and a map of the species structure forest in the study area. Analysis has shown that post-fire burns in forests are quite close to areas of strong compaction of isolines spring fire hazard. Such an arrangement of weather centers $\left(F_{I}\right)$ and nature (fire consequences) indicates the possibility of predicting active wildfires at the beginning of a fire hazardous season.

The results obtained are consistent with the conclusions of the authors in [2] that, according to climatic models, an increase in forest fire will be observed in the regions of Russia, which contributes to shift of boundaries of the middle taiga to more northern latitudes and, as a consequence, replacement of conifers by deciduous species. All this indicates the likelihood of continuation tendency increasing spring and autumn fire hazard in the forests of Priamurye region and, consequently, the activity of natural fires. 
(a)

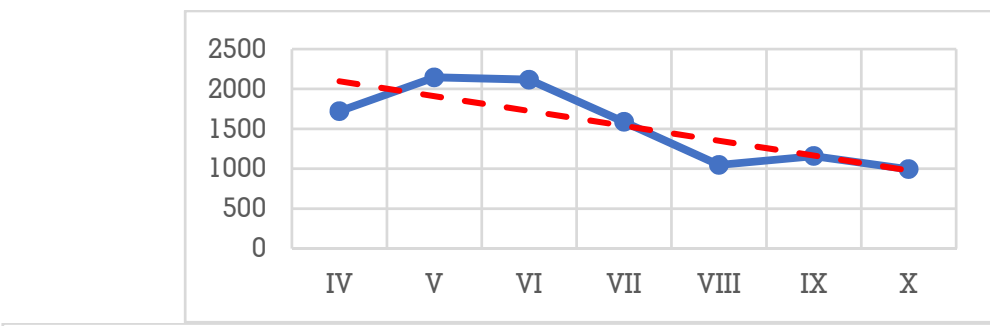

(b)

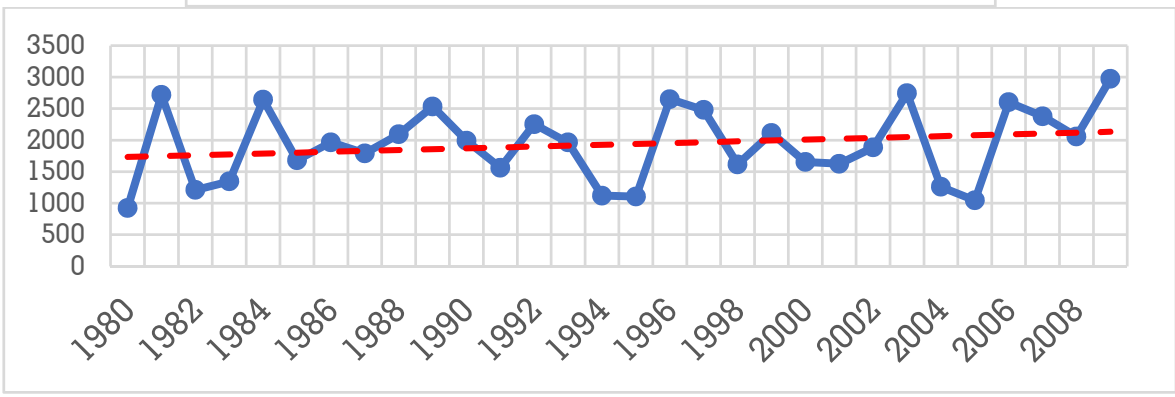

Fig. 3. (a) - Dynamics of the distribution fire hazard index for fire season (April-October) according to data of 50 meteorological stations for 1980-2009. (b) - Dynamics of the annual values of the spring fire hazard index according to the data of 50 meteorological stations for 1980-2009.

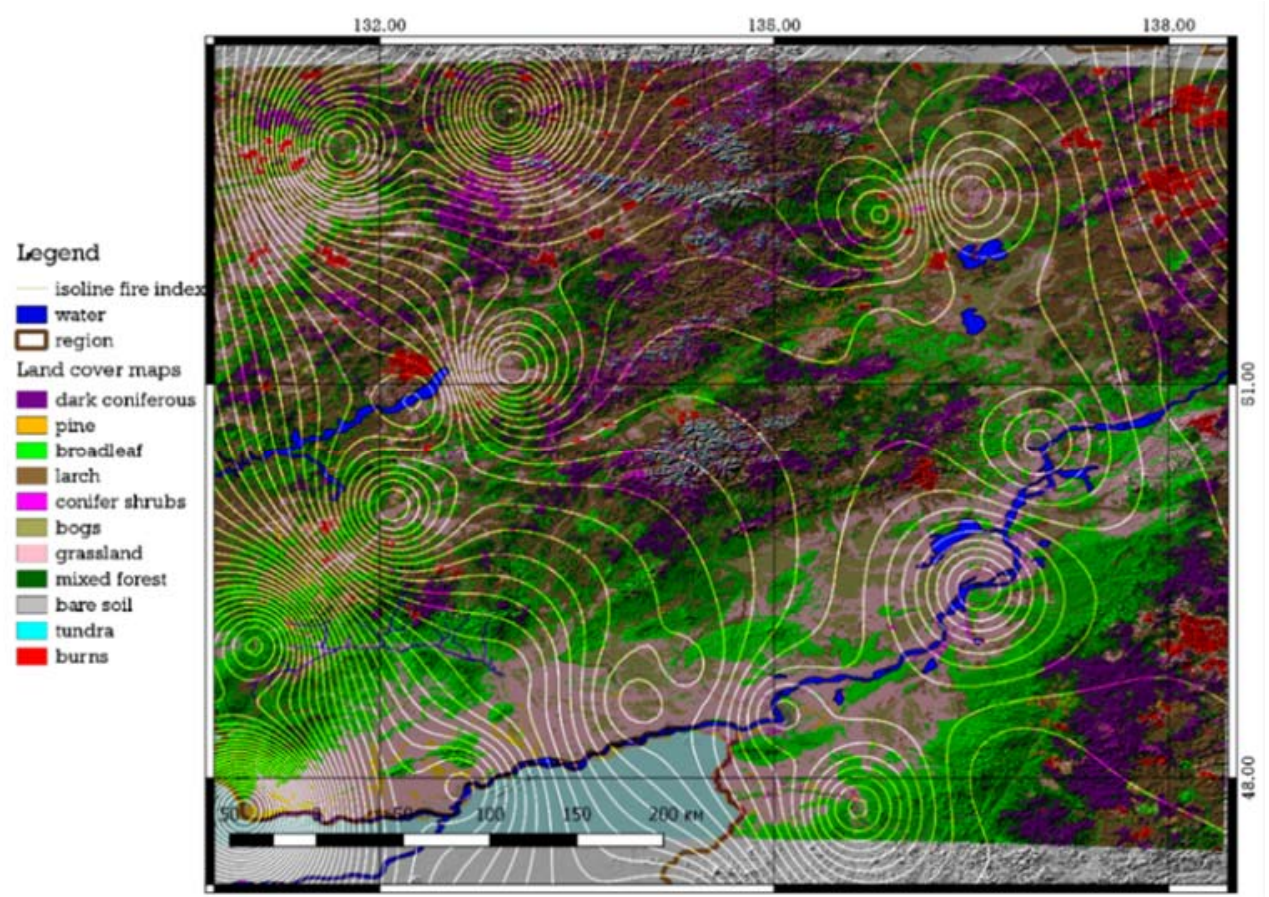

Fig. 4. Map of species structure forest in Priamurye region. Isolines of distribution average long-term values of fire hazard index in spring.

\section{Conclusions}

Annual forest fires, which change structure and area of forests, pose a danger in forested watersheds, where main flow of the Amur River is formed. Studies of the response of watercourses to changes in forest cover of watersheds, carried out earlier [1] within 
framework of one main problems of hydrology [9], were continued by authors of this work in order to obtain a predictive assessment of hydrological consequences. The following results were obtained:

1. The fire hazard $F_{I}$ was assessed based on meteorological data of 50 stations Amur region (Fig. 1) for fire hazardous season (April-October) of the climatic period 1980-2009, according to method of M.A. Sofronov [10].

2. The risk of natural fires in Amur region in spring is two times higher than in autumn (Fig. 3 ). Moreover, spring fires in the southern regions of the Khabarovsk Territory account for $50 \%$ of all fires per year [8].

3. The southern part of Khabarovsk Territory (Fig. 4) has an increased risk of active spring fires (more than 10 districts). Using the method [8] in fire mode on south of Khabarovsk Territory, two peaks of active fires were found for spring period (from March to June).

4. The general direction of the dynamics average over a 30 -year period of $F_{I}$ indices has a positive trend with greatest increase in the trend of spring (Fig. 3b). This indicates a possible continuation of long-term linear trend of fire hazard according to weather conditions. Moreover, such a probability will remain, despite the annual fluctuations in $F_{I}$, for example, in the spring, within 700-3000 units.

Thus, results obtained allow us to assert that the downward trend in coniferous forests, which burn faster and recover more slowly, will continue. The anticipated aggravation of the forest fire situation and, as a consequence, the possible reduction in areas of coniferous forests in river watersheds will contribute to occurrence of hydrological consequences:

- an increase in the height of rain floods, including in dry years;

- an increase in summer runoff indicators (discharge and runoff module), including in dry years.

Atmospheric precipitation flowing from post-fire burns into river beds will increase the flow of suspended solids, change hydrochemistry of rivers and worsen drinking water indicators.

\section{References}

1. G.V. Sokolova, A.L. Verkhoturov, S.P. Korolev, Geosciences, 9 (2019)

2. I.O. Torzhkov, E.A. Kushnir, A.V. Konstantinov et al., Russian Meteorology and Hydrology, 44 (2019)

3. I.I. Mokhov, V.A. Semenov, Russian Meteorology and Hydrology, 41 (2016)

4. S.I. Seneviratne, N. Nicholls, D. Easterling et al., Managing the Risks of Extreme Events and Disasters to Advance Climate Change Adaptation, Field, C.B.; Barros, V.; Stocker, T.F.; Qin, D.; Dokken, D.J.; Ebi, K.L.; Mastrandrea, M.D.; Mach, K.J.; Plattner, G.-K.; Allen, S.K.; Tignor, M.; Midgley, P.M. (eds.), A Special Report of Working Groups I and II of the Intergovernmental Panel on Climate Change (IPCC) (Cambridge University Press, 2012)

5. H. Hayasaka, K. Yamazaki, D. Naito, Polar Science, 22 (2019)

6. H. Hayasaka, K. Yamazaki, D. Naito, Journal of Disaster Research, 14-4 (2019)

7. E. Kalnay, M. Kanamitsu, R. Kistler et al., Bulletin of the American Meteorological Society, 77 (1996)

8. H. Hayasaka, G.V. Sokolova, A. Ostroukhov, D. Naito, Remote sensing, (2020) (in the press)

9. G. Blöschl, Marc F.P. Bierkens, A. Chambel et al., Hydrological Sciences Journal, 64 (2019) 
10. M.A. Sofronov, System of pyrological characteristics and evaluations as a basis for fire management in boreal forests, $\mathrm{PhD}$ thesis, (1998)

11. G.V. Sokolova, S.V. Makogonov, Russian Meteorology and Hydrology, 38 (2013) 